\title{
FORMAÇÃO INICIAL E FORMAÇÃO CONTINUADA DE PROFESSORES ANVERSO AO USO DAS TECNOLOGIAS
}

\section{ARTIGO ORIGINAL}

SANTOS, Maria Eduarda dos ${ }^{1}$

SANTOS, Maria Eduarda dos. Formação inicial e formação continuada de professores anverso ao uso das tecnologias. Revista Científica Multidisciplinar Núcleo do Conhecimento. Ano 05, Ed. 02, Vol. 04, pp. 05-13. Fevereiro de 2020. ISSN: 2448-0959, Link de acesso: https://www.nucleodoconhecimento.com.br/educacao/professores-anverso

\section{RESUMO}

Este trabalho tem como objetivo discutir o processo de Inclusão das novas tecnologias em ambiente escolar, analisando as formações iniciais e continuadas dos professores frente a este novo processo que chega as escolas e que está presente na vida dos alunos, tendo em vista a falta de profissionais qualificados, que desconhecem as ferramentas tecnológicas e suas respectivas utilizações na educação. Dessa forma, debateremos sobre a educação e tecnologia como uma relação necessária, o uso das tecnologias na aprendizagem do aluno e a formação dos professores voltada as tecnologias. Para isso, o artigo desenvolve-se a partir de uma pesquisa metodológica de cunho bibliográfico.

Palavras Chaves: Formação, tecnologias, professor, educação.

1 Pós-Graduada em Pedagogia: Atendimento Educacional Especializado na Perspectiva da Educação Inclusiva- FACOL Faculdade Escritor Osman da Costa Lins e Especialização em Libras pela UNIVASF- Universidade Federal do Vale do São Francisco. 


\section{INTRODUÇÃO}

No âmbito educacional atual, nos deparamos com alunos integralmente diferentes de alguns anos atrás, principalmente quando se refere as novas tecnologias; dessa forma, para atender essa nova demanda é necessário que os professores também escoltem o desenvolvimento das novas gerações, tornando o sistema educativo ainda mais atrativo para esse público alvo.

Considerando este contexto, as formações iniciais e continuadas dos professores devem abranger as questões referentes as novas tecnologias digitais, pois o uso das mesmas não se restringe apenas ao uso do computador ou da internet, aberto que essas ferramentas são a base para que o processo tecnológico nas escolas comece a fluir.

De tal modo, vale ressaltar a precisão de competência frente às novas tecnologias, ponderando assuntos anverso a uma realidade miscigenada de mudanças, mas que levam também aos avanços que a educação brasileira em si carece e as questões que evitam um desempenho significativo na formação do professor frente às novas tecnologias.

Diante desse contexto, tentar-se-á responder as seguintes perguntas: E qual será o papel do professor diante dessas tecnologias? Será que todos os educadores estão preparados para esse novo meio? Qual a relação estabelecida entre a tecnologia e a educação?

Neste sentido, o objetivo geral desta pesquisa é compreender teoricamente o processo de formação dos professores diante do novo cenário tecnológico, assim como avaliar as possíveis causas, consequências e avanços que a utilização dessas novas ferramentas poderá trazer para o sistema educativo.

Para tanto, procura-se verificar a preparação das escolas, professores, alunos e familiares, analisar como deverá ser inserido este processo de inclusão da tecnologia, reconhecendo ainda a necessidade de os profissionais da educação disporem de 
várias formações tanto iniciais como continuadas para que saibam utilizar de maneira significativa em seu cotidiano profissional.

A proposta metodológica escolhida para dar subsídio a este trabalho adotou a linha da pesquisa do tipo bibliográfica, que segundo Gil (2002, p. 45), "A pesquisa bibliográfica é desenvolvida com base em material já elaborado, constituído principalmente de livros e artigos científicos". Portanto, no decorrer desta pesquisa haverá conceitos e julgamentos não apenas de autores relevantes, e especialistas na área como também as opiniões, dos personagens do trabalho, trazendo dessa maneira um aperfeiçoamento e novos caminhos para o que será discutido ao longo da pesquisa.

Portanto, o presente artigo se dirige ao estudo dos pontos relacionados à formação do professor frente às novas tecnologias; abordando desta forma a precisão de maior preparação dos professores para 0 incremento de atividades com utilização recorrente dos recursos tecnológicos em sala de aula, salvo que este processo ajudará indiscutivelmente nas dificuldades que o mesmo apresenta nas questões metodológicas, na dinamização das atividades pedagógicas perante os recursos tecnológicos, entre outros.

Porém encontra-se neste meio a ausência de motivação e falta de políticas públicas no investimento da formação pedagógica do professor alusivo a esse assunto, dessa maneira surgem consequências na educação pois existe a carência de preparo do professor para conseguir lidar com esses novos recursos tecnológicos e passar a utilizá-los como ferramenta educacional frequentemente.

\section{EDUCAÇÃO E TECNOLOGIA: UMA RELAÇÃO NECESSÁRIA}

Atualmente, a educação conta com um público bem diferente, dessemelhante no sentido de serem alunos que apresentam uma comunicação mais atualizada, onde a mesma acontece por meio de imagens, sons e textos, porém a diferença é que estes aspectos estão inteiramente ligados as novas tecnologias. 
Para isso, cabe a escola dispor desses recursos metodológicos, e só isso também não basta, pois existe a necessidade de que os profissionais da educação, ou seja, os professores estejam capacitados para a utilização dessas mídias. Para que essa integração ocorra significativamente deve haver por meio de todos uma preocupação quanto ao objetivo que essas tecnologias trazem consigo.

Deve-se deixar claro que a tecnologia não substituirá o professor, como já foi difundindo algum tempo atrás, pelo contrário, a mesma vem a ser uma aliada a educação pois as tecnologias vem para servir as pessoas, e cabe ao professor comandar, reforçando assim suas aulas e tornando-as mais atrativas para os alunos, que a cada dia estão com uma visão voltada para as mídias tecnológicas, focando sua atenção para tudo que seja tecnológico. (FREIRE, 2001, p.198) afirma que: "faço questão de ir me tornando um homem do meu tempo [...] Como educador, acho que o computador, o vídeo, tudo isso é muito importante".

Observa-se que a educação vive um processo de contradição ao mundo atual, pois os alunos contemporâneos vivem em um mundo onde as ciências e as tecnologias por exemplo, influenciam cotidianamente suas vidas, ao mesmo tempo a educação não alcança esta constante modificação, muito menos induze ao cotidiano do educando cogitações sobre o mundo em que ele vive e os porquês de cada alteração, isso acontece quando a escola não dispõe de laboratórios de informática ou outros instrumentos tecnológicos existindo dessa forma esse paradoxo.

Dessa maneira Gadotti afirma que:

Na sociedade da informação, a escola deve servir de bússola para navegar nesse mar do conhecimento, superando a visão utilitarista de oferecer informações "úteis" à competitividade, para obter resultados. Deve oferecer uma formação geral na direção de uma educação integral. (GADOTTI, 2000, p. 250).

Assim, o autor reforça a necessidade de a escola estar inserida neste novo mundo para que o sistema educativo possa estar sendo desenvolvido por completo, pois essa 
necessidade surge devido a mobilização do grande uso das tecnologias por todos, independente da classe social que este esteja inserido, e para que essa inclusão aconteça deve-se repensar sobre o ensino, adaptando o mesmo a esta nova sociedade.

Isto reforça a relação necessária que a educação precisa exercer com a tecnologia, onde Mercado (2002) mostra que:

[...] as instituições educacionais enfrentam o desafio não apenas de incorporar as novas tecnologias como conteúdo do ensino, mas também de reconhecer as concepções que os aprendizes têm sobre estas tecnologias para elaborar, desenvolver e avaliar práticas pedagógicas que promovam o desenvolvimento de uma disposição reflexiva sobre os conhecimentos e os usos tecnológicos. (MERCADO, 2002, p. 49).

O autor desta forma propõe que, a relação escola/tecnologia precisa começar a agir e lutar contra os desafios que são encontrados pois o contato dos educandos proporcionará aos mesmos um desenvolvimento ainda mais significativo. É preciso ter em mente que em uma sociedade contemporânea onde tudo gira em torno das tecnologias, a escola também deve ser inserida neste contexto e se atualizar, deixando um pouco de lado o modelo tradicionalista de apenas transmitir conhecimentos.

\section{O USO DAS TECNOLOGIAS NA APRENDIZAGEM DO ALUNO}

A utilização dos recursos tecnológicos no ambiente escolar cativa o desenvolvimento do aluno no sentido de este começar a ter um acesso maior nas informações que amparará, um pensamento crucial e fecundo deste educando e que resultará, portanto que o aluno se depare com novas descobertas, como por exemplo costumes e regras diferentes, o que auxiliará o mesmo a busca da inovação.

No entanto, não basta apenas colocar um computador em sala de aula, é necessário a compreensão de que o instrumento tecnológico não é simplesmente um ponto 
básico na metodologia de ensino e aprendizagem, devemos tê-los como aparelhos que proporcionalizarão a intervenção mais próxima entre educador, educando e os conteúdos escolares; desta forma, é significativamente eficaz que se analise o velho modelo pedagógico até o momento implantado, buscando agora novas fronteiras que incorporam o novo, neste caso a (tecnologia) ao envelhecido.

E neste sentido, Vieira relata que:

[...] a implantação da informática como auxiliar do processo de construção do conhecimento implica mudanças na escola que vão além da formação do professor. É necessário que todos os segmentos da escola - alunos, professores, administradores e comunidades de pais estejam preparados e suportem as mudanças educacionais necessárias para a formação de um novo profissional. (VIEIRA, 2011, p. 4).

Sendo assim, entende-se que a utilização da tecnologia na educação é atualmente uma necessidade intransferível, e que já ganha grandes reconhecimentos pelos profissionais da educação. Porém acende-se a necessidade de uma busca de como atrair mais motivação para a sala de aula através dessas ferramentas, e nesse contexto a precisão de formações para estes profissionais no sentido de utilizar a tecnologia para aprimorar efetivamente o aprendizado de seus alunos é fundamental.

Isto é confirmado por Oliveira (2004, p.50): "Educar para a comunicação, "educação para a mídia", "educar com os meios", "educomunicação" "mídiaeducação", caracterizam conceitos que discutem a inclusão das mídias no espaço escolar, tanto no aspecto educacional, como no comunicacional." Esta afirmativa avigora a seriedade de um elo de ligação estabelecido entre a comunicação tecnológica com a metodologia educacional, dirigindo-se a uma conexão com suas atividades.

Portanto, o uso tecnológico em sala de aula proporciona alguns benefícios, entre eles está o aperfeiçoamento na qualidade educacional, pois adapta novos caminhos para o ensino-aprendizagem; outro fator está na redução da reprovação e consequentemente evasão escolar, isto porque as ferramentas tecnológicas trazem 
facilidades na busca de informações e esclarecimentos das dificuldades que surgirem, desencadeando neste momento o empenho pelos estudos, por conseguinte uma melhoria no desempenho escolar deste educando pois as horas de estudo serão maiores, visto que a busca por informações não acontecerá apenas na sala de aula, elas se estenderão para suas casas, despertando assim a curiosidade e abrindo portas para novas descobertas.

Para que tudo isso ocorra é necessária, no entanto, formações para os professores e informações sobre o assunto não apenas para os alunos, mas também para todos os familiares, criando desta forma uma socialização ainda melhor para a aprendizagem. Segundo Oliveira, Suaiden e Tarapanoff (2002, p. 5): "Não poderá haver sociedade da informação sem cultura informacional e que o maior problema da inclusão digital não é a falta de computadores, mas o analfabetismo em informação". Neste contexto, o investimento de políticas públicas neste segmento é imprescindível.

\section{FORMAÇÃO DOS PROFESSORES VOLTADA AO USO DAS TECNOLOGIAS}

Até o presente momento é entendido que a correspondente preparação do professor é o elemento básico para a utilização não apenas do computador, mas também de todas as outras mídias tecnológicas que auxiliem a um avanço e melhoria no processo educativo.

A realidade é que nem todos os professores estão preparados, alguns se arriscam e tentam fazer uso das tecnologias e o que ocorre na maioria dos casos é que os alunos detêm maiores saberes sobre estes instrumentos que seus professores, e neste caso o educando ensina o educador. Diante disso, o papel do professor é entender e incluir sua própria prática em meio este novo cenário, buscando mudanças para seu crescimento profissional e desenvolvimento dos alunos.

Neste cenário de transformação, o educador necessita ter ciência de como guiar os educandos oferecendo referências de onde e como colher informação, e como fazer uso da mesma de acordo com o contexto que irá ser solicitado. O professor constituirá 
ainda uma ponte no processo de aprendizagem dos alunos, estará nesse contexto excitando o trabalho individual, ao mesmo tempo que estará também amparando o trabalho em equipe agregados por campo de interesses.

Contudo, a formação dos professores voltadas para esses recursos tecnológicos deve acontecer à medida que esta projeta a perspectiva de uma disseminação de informações de cunho pedagógico de forma mais rápida. Dessa maneira, Almeida e Valente ressaltam que deve haver:

[...] condições para que ele construa conhecimento sobre as técnicas computacionais, entenda por que e como integrar o computador na sua prática pedagógica e seja capaz de superar barreiras de ordem administrativa e pedagógica. (VALENTE E ALMEIDA 1997, P. 08).

O professor diante de todas essas percepções, deve então estar bastante envolvido com a metodologia educativa, criando pontes de ligação entre seus conteúdos e as modernizações constantes que surgem ao longo do processo educativo, mostrandose nesse contexto um profissional ciente dos arranjos pedagógicos, que começa a utilizar múltiplos recursos e métodos em busca do fortalecimento das metodologias referentes ao ensino-aprendizagem.

Araújo (2005) relata ainda que:

O valor da tecnologia na educação é derivado inteiramente da sua aplicação. Saber direcionar o uso da Internet na sala de aula deve ser uma atividade de responsabilidade, pois exige que o professor preze, dentro da perspectiva progressista, a construção do conhecimento. (ARAÚJO 2005, P.23).

Com isso, percebemos que o processo de inserção das tecnologias na escola precisa de uma atenção especial, pois é preciso um verdadeiro engajamento para que esta ferramenta seja utilizada apenas para a construção do conhecimento, e desta forma os alunos não esqueçam o verdadeiro significado do uso tecnológico em sala de aula 
e não utilize-a apenas para estar conectado em redes sociais, este último constitui-se um grande problema encontrado pelos professores em sala.

A questão seguinte vem de questionamentos referentes ao perfil desse educador diante desse novo contexto, e para isso existe referências de que este profissional deve estar aberto a mudanças e comprometido com essas transformações, constituindo dessa maneira o primeiro passo, além disso este ainda precisa ser interativo com seus alunos e competente quanto as propriedades das tecnologias.

Sampaio traz a seguinte questão:

A preocupação com o rumo das mudanças tecnológicas impõe à área da educação um posicionamento entre tentar entender as transformações do mundo, produzindo conhecimento pedagógico sobre ele e auxiliando o homem a ser sujeito da tecnologia[...]. (SAMPAIO, 1999, p.29)

Nesse contexto, A formação dos educadores implica em uma preparação do currículo com um contorno inovador que, ao superar aquele modelo muito tradicional de ensino, colocará novidades na ponte estabelecida entre a teoria e a prática, onde irá instigar no sistema educativo questões melhores para envolver a interdisciplinaridade consentindo ao docente a se adaptar neste ambiente tecnológico.

\section{CONCLUSÃO}

A tecnologia em si possui um expressivo choque no que se refere o papel dos professores, primeiro pela constante modificação e renovação que esta sempre recebe, e segundo quanto a utilização da tecnologia, somado aos conteúdos, métodos em sala de aula, amparando um novo modelo de educação que insere os alunos como participantes em seu próprio processo de aprendizagem, trazendo inovações e saindo do modelo tradicionalista de apenas receber informações.

Desta forma percebe-se ao decorrer deste trabalho que o investimento em formações e o estímulo dos professores a um novo processo educativo buscando a reformulação 
de suas aulas e o maior contato e troca de informações com seus alunos irá despertálos para que possam ir em busca de novos conhecimentos que irá se conectar com suas experiências escolares e consequentemente com sua experiência de vida também.

É preciso um entendimento por meio de todos que a formação de professores é imprescindível e indispensável, pois é preciso que todos estejam inseridos nessa renovação tecnológica existente, e os ambientes escolares em si carece de disponibilizar em seu currículo um projeto tecnológico flexível e atualizável de fácil compreensão para ir além da escola, e envolver todos os familiares nessa ação também.

Percebemos dessa forma que a inserção da tecnologia em ambiente escolar constituise hoje como uma ferramenta primordial e sendo um artifício de contribuição na contextualização do ensino e para que seu papel seja cumprido em seu real significado, o governo precisa investir em formações tanto iniciais quanto continuadas para que o mesmo consiga não apenas saber utilizar um computador por exemplo, mas que utilize essa ferramenta como um meio de interação no espaço educacional.

\section{REFERÊNCIAS}

ARAÚJO, Rosana Sarita de. Contribuições da Metodologia WebQuest no Processo de letramento dos alunos nas séries iniciais no Ensino Fundamental. In: MERCADO, Luís Paulo Leopoldo (org.). Vivências com Aprendizagem na Internet. Maceió: Edufal, 2005.

FREIRE, Paulo. A Educação na Cidade. 5. ed. São Paulo: Cortez, 2001a.

GADOTTI, Moacir. Perspectivas Atuais da Educação. Porto Alegre: Artes Médicas Sul, 2000.

GIL, A. C. Como elaborar projetos de pesquisa. São Paulo: Atlas, 1988 
MERCADO, Luís Paulo Leopoldo. "Formação docente e novas tecnologias. In" Novas tecnologias na educação: reflexões sobre a prática. Maceió: Edufal, 2002.

OLIVEIRA ,Márcio Romeu Ribas de. O Primeiro Olhar: Experiência com Imagens na Educação Física Escolar. 2004. 177f. Tese (Mestrado em Educação Física) Centro de Desportos - Universidade Federal de Santa Catarina/UFSC

SAMPAIO, Marisa Narciso. Alfabetização tecnológica do professor. Petrópolis, RJ: Vozes, 1999

VIEIRA, Rosângela Souza. O papel das tecnologias da informação e comunicação na educação: um estudo sobre a percepção do professor/aluno. Formoso - BA: Universidade Federal do Vale do São Francisco (UNIVASF), 2011.

VALENTE, José Armando; ALMEIDA, Fernando José de. Visão analítica da informática na educação no Brasil: a questão da formação do professor. Revista Brasileira de Informática na Educação, Florianópolis, v. 1, 1997.

Enviado: Janeiro, 2020.

Aprovado: Fevereiro, 2020. 